\title{
Polyepichlorohydrin modified quartz crystal microbalance sensor for sulfur mustard vapor detection
}

\author{
Rajendra Bunkar *, Ram Asrey, K.D. Vyas, V.K. Rao, Sunil Kumar, A.R. Srivastava and M.P. Kaushik \\ Defence Research \& Development Establishment (DRDE), Jhansi Road, Gwalior, M.P., 474002, India \\ rajbunkar.drdo@gmail.com*
}

\begin{abstract}
The sulfur mustard (SM) vapor sensitive property of polyepichlorohydrin (PECH) polymer coating was investigated by using quartz crystal microbalance (QCM) sensor. The measurements were based on the frequency shifts $(\mathrm{Hz})$ due to the sorption of SM vapor in the polymer coating of the modified QCM. The response of QCM sensor was found to be about $410 \mathrm{~Hz}$ for SM vapors. The influences of coating thickness and temperature on the sensor response were examined. The sensor showed optimum response and reversibility at $4 \mathrm{KHz}$ of coating thickness and lower temperature. The relevant detection parameters like sensitivity, reversibility and reproducibility were evaluated for SM detection.
\end{abstract}

Keywords: PECH, QCM, sulfur mustard, response, reversibility.

Introduction

The Analysis of air contaminants is very essential to meet industrial hygiene and government pollution standards. The detections of pollutants and war gases are utmost important not only for industrial workers but also for civilians. Apart from detections of the air pollutants, chemical warfare agents (CWA) detection is also essential before taking necessary steps for protection (Singh \& Bhise, 1999). Sulfur mustard (SM) is known as king of CWA which causes alkylation reactions with DNA and results in physiological and metabolic disturbances (Vidan et al., 2002). Various methods are reported in literature for detection of nerve agents and their simulants but no report is available for detection of organosulfur compounds by QCM sensor. QCM sensors are relatively cheaper devices which provide high sensitivity near ambient operating conditions. These mass sensitive devices are based on piezoelectric phenomenon. According to Sauerbrey's equation the relation between frequency change and mass is as follows:

$$
\Delta \mathrm{F}=-2.3 \times 10^{6} . \mathrm{F}^{2}(\mathrm{Ms} / \mathrm{A})
$$

Where $\Delta \mathrm{F}$ and $\mathrm{F}$ is change in frequency and basic frequency of piezoelectric crystal respectively. Ms is mass on piezocrystal surface, $A$ is surface area of crystal $\left(\mathrm{cm}^{2}\right)$ on which coating has been applied (Gupta \& Gutch, 2004). The polymers offer a great advantage as sorbent coatings for detection of volatile organic compounds (VOC's) by using QCM sensors because apart from stable film they also provide specific interactions with particular analyte (Adhikari \& Majumdar, 2004). In present study we report the detection of the SM by using QCM sensor in ambient condition. The various detection parameters like coating thickness and temperature were also optimized for this study.

Materials and methods

The SM was synthesized in the laboratory and was found to be more than $99 \%$ pure by GC/GC-MS analysis. The polyepichlorohydrin material was purchased from Sigma-Aldrich (CAS No. 24969-06-0).

Caution: SM is a blistering agent so it must be handled by wearing hand gloves.

The time dependent frequency shifts and reversibility of modified QCM sensor were recorded by using experimental setup shown in Fig 1. A piezoelectric crystal connected with oscillator circuit and frequency counter (Aplab $1.3 \mathrm{GHz}$ frequency counter 1122) and computer was housed in a glass tube. Nitrogen gas also connected through flow meter to this housing. The modified sensor was purged by $\mathrm{N}_{2}$ for 10 minutes to get stable base line. Temperature control of the sensor was achieved by placing it in contact with a single thermoelectric cooler (Peltier device). A control circuit with a set point monitors the temperature and adjusts the cooler power.

Fig.1. Schematic diagram of the sulfur mustard vapor detection system.
Research article

CIndian Society for Education and Environment (iSee)
"QCM sensor for sulfur mustard" http://www.indjst.org
Bunkar et al. Indian J.Sci.Technol. 
The time dependent frequency shifts of sensor was recorded upon exposure of SM vapor in each response cycle. First sensor was exposed by SM vapors for one minute in response cycle. The exposed concentration was detected equivalent to 4 to 5 levels of $\mathrm{AP}_{2} \mathrm{C}$ (Proengin-Etat Francais). The concentration of sulfur mustard vapor exposed on sensor was calculated by using diffusion method and further confirmed by trace GC-FPD (Thermo electron corporation) (Gary O Nelson, 1992). Then SM exposure was stopped by closing the valve and $\mathrm{N}_{2}$ was purged on the sensor for two minutes at flow rate of $200 \mathrm{CC} / \mathrm{min}$ to attain the original frequency in recovery cycle. These cycles were repeated seven to eight times to get overall response pattern.

\section{Deposition of sensitive layer}

A spherical quartz piezoelectric crystal $(10 \mathrm{MHz}$ basic frequency, AT cut, $7 \mathrm{~mm}$ diameter, $0.2 \mathrm{~mm}$ thickness with circular gold electrodes) was modified with $\mathrm{PECH}$. It was used as a sensitive material and deposited onto the surface of QCM by a solution-coating method. The method was chosen due to its simplicity, feasibility and possibility to obtain good quality uniform film (Ying et al., 2007). A small amount of $\mathrm{PECH}$ was dissolved in DMF, and subsequently the solution was dropped carefully onto the center of the electrode by a $5 \mu \mathrm{L}$ micro syringe (Hamilton). Then the coated QCM was dried at $100^{\circ} \mathrm{C}$ for $1 \mathrm{~h}$ to obtain stable films. When the solvent was evaporated, a solid film was deposited on the electrode surface. The procedure was repeated until a desired thickness was achieved, which resulted about $4 \mathrm{kHz}$ decrease of the QCM frequency.

\section{The PECH material}

The essential criterion before selecting a polymer coating for sensor application is the specific and reversible interaction between analyte of interest and polymer. The functional groups in the molecular structure of polymer are responsible for the weak reversible interactions like hydrogen bonding and Van der Waals interaction etc. The way to increase the sensitivity of the sensor is the selection of a high sensitive polymer coating for the analyte which is to be detected (Du et al.,
Vol. 3 No. 2 (Feb 2010)

ISSN: 0974- 6846
Scheme 1: Structure of polyepichlorohydrin

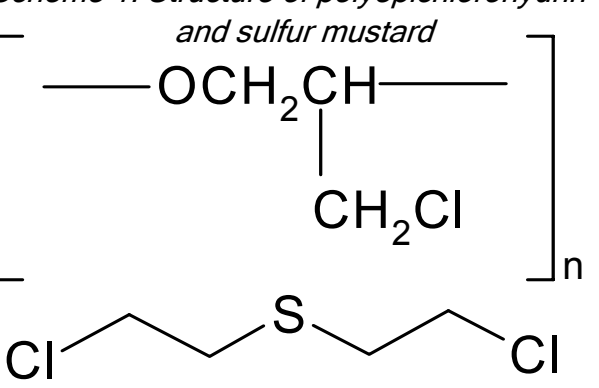

2008). The commercially available $\mathrm{PECH}$ was used as sensing coating for the detection of SM. The structure of PECH and SM is depicted in Scheme 1. the polymer is approx. 70,000 by GPC. The PECH was selected as a coating material because of commercial availability and specific probable reversible interaction between SM and The average molecular weight of

polymer depicted in Scheme 2.

\section{Results and discussion}

The frequency shift observed upon application of a thin film of polymer material to a bare QC surface is caused primarily by the mass of the material. When vapors are absorbed by polymer films, both the film mass Scheme 2. The probable interaction of and film modulus are perturbed, with SM and PECH film (a) Hydrogen (b) van der waals interaction the latter causing the larger change in signal. The literature reports the application of the $\mathrm{PECH}$ as sensitive material for the detection of the mustard gas by using array of 158 $\mathrm{MHz}$ SAW single delay line sensors. The sensing system shows 200 to 300 $\mathrm{Hz}$ of steady state response at 2 $\mathrm{mg} / \mathrm{m}^{3}$ vapor concentration. It merely elaborates the effect of various interference and $\mathrm{RH}$ on SAW based detection (Grate \& Klusty, 1993). In the present study we report the QCM based detection of the SM in ambient condition. The coating thickness and temperature is optimized and the probable sensing mechanism is proposed for the SM detection. The PC-QC is directly

Fig.2. SEM image of central area of the PC-QC at 3000 magnification (Inner image at 12000 magnifications)

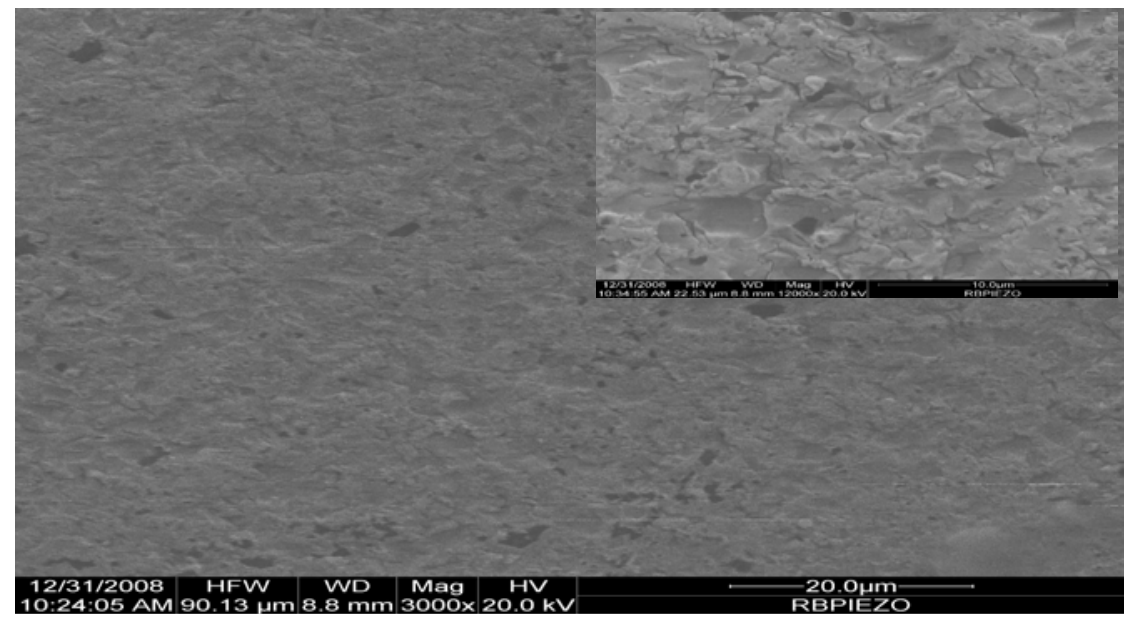

used for the surface characterization by scanning

"QCM sensor for sulfur mustard"

Bunkar et al. http://www.indjst.org 
electron microscope (FEI Quanta 400). The SEM micro graph observed at magnification of 12000 and 3000 which reveals that almost $95 \%$ of the electrode is uniformly coated with $\mathrm{PECH}$ polymer (Fig. 2).

The resonant frequencies of the sensor were measured after the deposition of the $\mathrm{PECH}$ film. When sulfur mustard vapor exposed on QCM sensor its frequency started decreasing and frequency change $(\Delta \mathrm{F}$ in $\mathrm{Hz})$ increases with respect to time. The sensor attains its initial frequency after exposing it with nitrogen in recovery cycle. The time (in seconds) and frequency drift $(\Delta F$ in $\mathrm{Hz})$ observed at $X$ axis and $Y$ axis respectively in response pattern.

The real-time measurement of $\mathrm{PECH}$ coated device for sulfur mustard vapors shown in Fig. 3a. It is observed that change in frequency is directly proportional to the amount of the sulfur mustard sorbed on the modified QCM sensor and it increases continuously in response cycle. The sensor is tested against $155 \mathrm{ppm}$ of the diffusion concentration and it shows $410 \mathrm{~Hz}$ response under ambient condition. The sensor exhibits good and fast response, reversibility with small baseline drift. The sensor shows $235 \mathrm{~Hz}$ response after 8 months of coating (Fig. 3b). Average response has been calculated by averaging per unit centimeter height of the maximum and minimum signal. Furthermore the frequencies of the QCM sensor attained almost original values after desorption processes in recovery cycle.

The probable reason of the sensing might be attributed to the mass change and subsequently the frequency change of QC because of cumulative effect of interactions between SM and PECH film. The possible hydrogen bond and Van der Waals interactions between SM and film are depicted in scheme 2. Further the sorption of the SM into the PECH polymer framework provides the basis of the higher detection efficiency of the PC-QCM sensor (Adhikari \& Majumdar, 2004).

\section{Effect of coating thickness}

The sensitivity study of the QCM sensor has also been studied at various coating thickness (Fig. 4). The increased response was observed with increased coating thickness. The maximum response 410 and $428 \mathrm{~Hz}$ was observed at 4 and $5 \mathrm{KHz}$ of coating thickness respectively. The difference in response observed from 4 and $5 \mathrm{KHz}$ of coating thickness was marginal, so $4 \mathrm{KHz}$ coating was optimized for these experiments.
Vol. 3 No. 2 (Feb 2010)

ISSN: 0974- 6846
Fig.3. Real-time frequency shift measurement of PC-QCM sensor for SM detection (a) Initial and (b) final response.

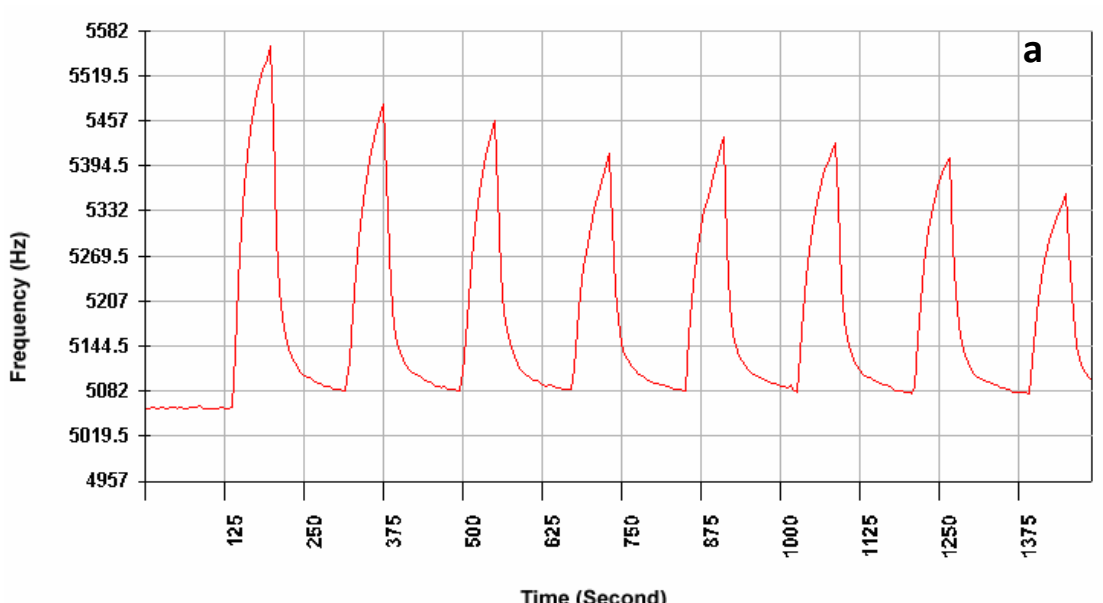

Time (Second)

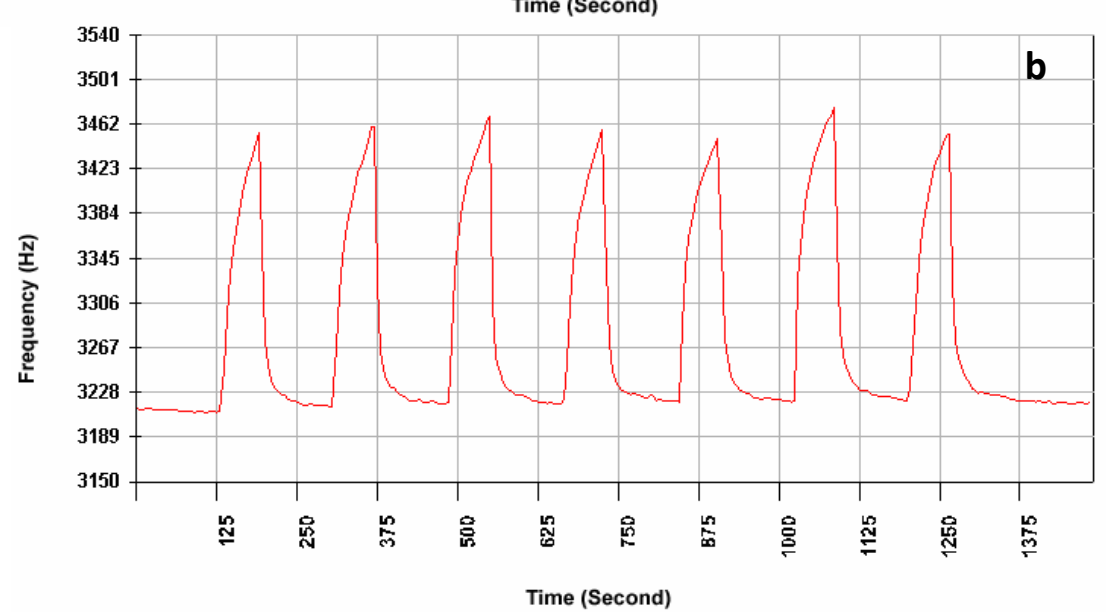

\section{Effect of temperature}

Temperature plays a significant role in sensing properties of QCM sensor. The effect of temperature on performance of sensor is shown in Fig. 5. The maximum sensitivity of the sensor was observed at lower temperature (below $20^{\circ} \mathrm{C}$ ). The decreased response was observed with increasing temperature. It might be possible due to weaker tendency of hydrogen bond formation and change in sorption strength of polymer at elevated temperature. It is reported that hydrogen bonding ability is temperature dependent and decreases with increasing temperature. Further the sorption strength of polymer is logarithmically related to reciprocal of temperature so the sorption of analyte vapor decreases drastically with increasing temperature (Grate \& Nelson, 2003). The small increase in temperature significantly affects the sorption of vapor into the polymer film resulting loss in the sensitivity of the QCM sensor. Polymer coatings are highly temperature-dependent and QCM sensors are quite sensitive to thermal expansion of the polymer on the surface, which leads to drift (Grate \& Klusty, 1993).
Research article

CIndian Society for Education and Environment (iSee)
"QCM sensor for sulfur mustard" http://www.indjst.org
Bunkar et al. Indian J.Sci.Technol. 
Fig.4. The effect of coating thickness upon frequency shift of the QCM sensor.

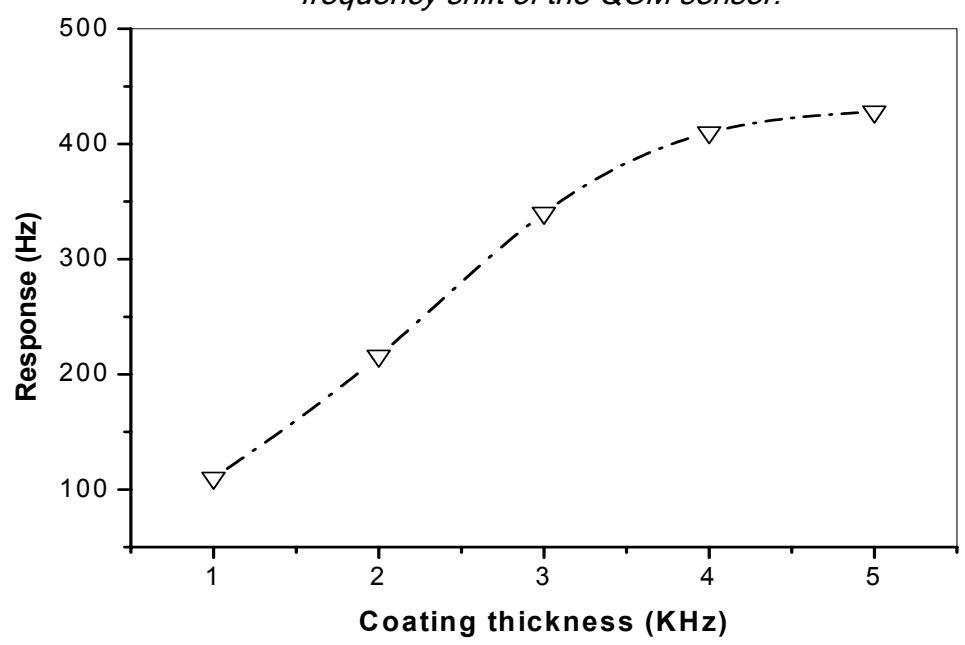

Conclusion

A Polyepichlorohydrin (PECH) modified quartz crystal microbalance (QCM) was used for detection of sulfur mustard (SM) vapor. The initial response of the sensor was $410 \mathrm{~Hz}$ with $\pm 10 \%$ variation at ambient diffusion concentration of SM vapor. The sensor has shown optimum response at lower temperature and $4 \mathrm{KHz}$ of coating. Thus PECH material coating on QCM sensor shows promising material for SM vapor detection.

\section{References}

1. Singh Beer and Bhise PP (1999) Silica gel detector tubes for toxic chemicals. J. Sci. Ind. Res. $58,25-30$.

2. Vidan A, Luria S and Eisenkraft A (2002) Ocular injuries Following Sulfur Mustard Exposure: Clinical Characteristics and Treatment. IMAJ. 4, 577-578.

3. Gupta DC and Gutch PK (2004) Fluorinated epoxy resin based sorbent coating material for quartz piezoelectric crystal detctor. Def. Sci. J. 54 (2), 229-234.

4. Adhikari B and Majumdar (2004) Polymers in sensor application. Prog. Polym. Sci. 29, 699-766.

5. Gary O Nelson (1992) Gas mixture preparation and control. pp: 112-120.

6. Ying Z, Jiang Y, Du X, Xie G, Yu J and Wang G (2007) PVDF coated quartz crystal microbalance sensor for DMMP vapour detection. Sens. Actuat. B: Chem. 125, 167-172.

7. Du X, Ying Z and Jiang Y (2008) PVDF coated quartz crystal microbalance sensor for DMMP vapor detection. Sens. Actuat. B. Chem. 134, 409-413.

8. Grate JW and Klusty M (1993) A Smart Sensor System for Trace Organic Vapor Detection. $183^{\text {rd }}$ Electrochemical Soc. Meeting, Honolulu, Hawaii.

9. Grate JW and Nelson DA (2003), Sorptive polymeric materials and photopatterned films for gas phase chemical microsensors. Proc. IEEE. 91(6), 881-889.

Fig.5. The response of PECH modified sensor at different temperatures.

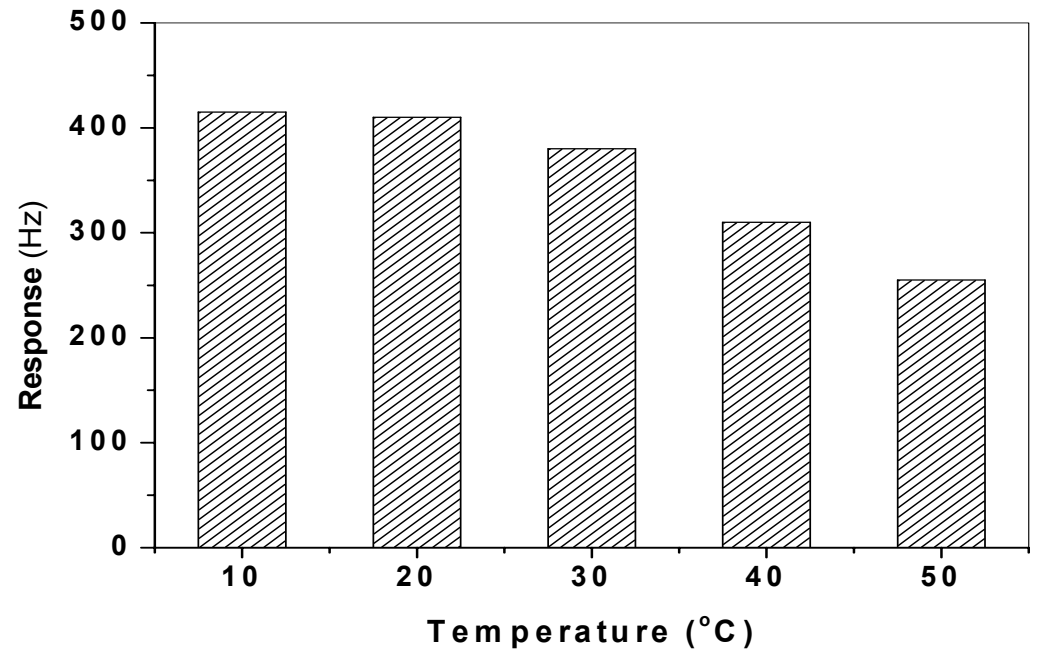

Acknowledgement

Authors are thankful to Dr. R. Vijayaraghavan, Director, Defence Research and Development Establishment (DRDE), Gwalior (M.P.) for providing laboratory facilities. Authors are also thankful to Dr. Beer Singh, Associate Director, DRDE for providing useful suggestions and motivation.

Research article

CIndian Society for Education and Environment (iSee)
"QCM sensor for sulfur mustard" http://www.indjst.org
Bunkar et al. Indian J.Sci.Technol. 